\title{
FIRE-RESISTANCE STUDY OF RESTRAINED STEEL COLUMNS WITH INITIAL LATERAL DISPLACEMENT
}

\author{
Jin Zhang ${ }^{1, *}$, Yi-Xiang $\mathrm{Xu}^{2}$, Xiao-Jing Yang ${ }^{1}$ and Dong-Hao Zhang ${ }^{1}$ \\ ${ }^{1}$ Key Laboratory of Concrete and Pre-stressed Concrete Structures of \\ the Ministry of Education, Southeast University, Nanjing, China \\ ${ }^{2}$ Department of Civil Engineering, Strathclyde University, Glasgow, UK \\ *(Corresponding author: E-mail: zhangjin0622@139.com)
}

Received: 12 June 2016; Revised: 13 February 2017; Accepted: 14 February 2017

\begin{abstract}
This study presents an analytical formula based on differential equations of equilibrium to analyse the behaviour of steel columns with initial lateral displacements in fire. The imperfections of the initial flexure of the steel columns are considered. Yielding of the edge fibres at the middle span of a column subjected to elevated temperature is designated as the failure criterion for the fire resistance of the column. After validating the results of the formula using ANSYS, a numerical application is performed to demonstrate the effects of different parameters on the ultimate load bearing capacity. The formula is then used to predict the axial force of axially restrained steel columns based on the displacement coordination condition; then, the axial force is verified by ANSYS. The axial displacement predictions from the proposed method correspond well with those obtained through the finite element method. The critical temperature can also be predicted by calculating the load bearing capacity and axial force at a certain temperature. The results show that the increase of initial lateral displacement and temperature decreases the bearing capacity of the steel column and that the critical temperature decreases with increasing constraint stiffness.
\end{abstract}

Keywords: Steel column, fire resistance, initial lateral displacement, load bearing capacity, critical temperature

DOI: $10.18057 /$ IJASC.2018.14.1.2

\section{INTRODUCTION}

Inclining steel columns can have insufficient fire resistance because of their lateral displacement, which can generate additional bending moments in the columns during an earthquake, leading to a higher maximum stress. Therefore, it is critical to investigate the fire resistance of steel members with initial lateral displacements.

A number of publications have described the effect of fire protection losses on the fire resistance of steel columns [1-5]. Unprotected steel structures do not have desirable fire resistance because the temperature of unprotected steel elements increases rapidly in fire due to the high thermal conductivity of steel. Shahria et al. [6] studied the fire performance curves of unprotected HSS steel columns. The moment-rotation behaviour, lateral load-deflection behaviour, stiffness and ductility of the columns at different axial load levels were the main parameters considered in their study. Corte et al. [7-8] studied the effects of structural damage caused by earthquakes on the fire resistance of steel columns and found that the impact of structural damage on fire resistance is more significant if the design of the steel structure only considers the ultimate limit state. Mohammad Hany Yassi [9] described the impact of a post-earthquake fire on the frame structure and proposed two approaches to study the damage caused by a post-earthquake fire. In the first approach, an equivalent static lateral load is applied to the structure to cause lateral deformation, after which the fire load is applied. The second approach is application of time history motion data, which was used to analyse the structure before applying the fire load. 
A column is often axially restrained by adjacent members in steel structures, such as slabs, beams, and supports. The restraint has a significant impact on the ultimate load bearing capacity of columns. At normal temperatures, the axial restraint can improve the ultimate load bearing capacity of the column [10]. Li and Guo [11] showed that restrained steel beams have better fire-resistance capabilities than isolated steel beams. Liu et al. [12] investigated the effect of restraints on steel beams during fire experiments. The restraint effect was found to be important for the behaviour of the beam in fire conditions; catenary actions were observed. Studies have also addressed the restraint of a column during a fire. Rodrigues et al. [13] showed that neglecting the effect of thermal axial restraints can caused the fire resistance of columns to be overestimated. Huang and Tan [14] proposed a Rankine approach that incorporated both the axial restraint and creep strain for critical temperature prediction of an axially restrained steel column. Li and Guo [15] analysed restrained steel columns during the cooling phase for safety evaluations and repairs of steel structures against fire. Ellobody and Young [16] presented a nonlinear 3-D finite element model investigating the behaviour of concrete-encased steel composite columns at elevated temperatures. Wang and Davies [17] performed tests to determine how bending moments in restrained columns would change and how these changes might affect column failure temperatures.

However, few studies have considered the effects of initial displacement. This paper presents an analytical model based on differential equilibrium equations to predict both the ultimate load bearing capacity of steel columns with initial lateral displacement and the critical temperature of axially restrained steel columns.

\section{ULTIMATE LOAD BEARING CAPACITY OF STEEL COLUMNS}

\subsection{Supported Steel Columns with Both Ends Hinged}

Steel columns can laterally move during a fire at either the top or bottom of the column. This paper assumes that the displacement occurs at the top and that the temperature of the entire column is uniform.

Figure 1 shows a mechanical model of a steel column with simply fixed boundary conditions and an initial lateral displacement at its top ends. It is assumed that every column in an actual building has some initial imperfections. The ultimate load bearing capacity for columns with initial imperfections is less than that of perfect columns. The initial flexure of a column can be expressed as

$y_{0}=a_{0} \sin \left(\frac{\pi x}{L}\right)+\frac{\delta \cdot x}{L}$

Where $\mathrm{L}$ is the length of the column, a 0 is the initial flexure at the mid-span of the column and $\delta$ is the initial lateral displacement.

According to the differential equation for equilibrium, if the lateral displacement of the column under the action of a vertical load is represented by $y$, then the following equation can be obtained: 


$$
E_{T} I\left(y-y_{0}\right)^{\prime \prime}+P\left(y+e_{0}-\delta\right)=0 \quad(0 \leq x \leq L)
$$

Where $\mathrm{E}_{\mathrm{T}}$ is the elastic modulus of steel at temperature $\mathrm{T}, \mathrm{e}_{0}$ is the load eccentricity distance, and $\mathrm{I}$ is the inertia moment of the column.
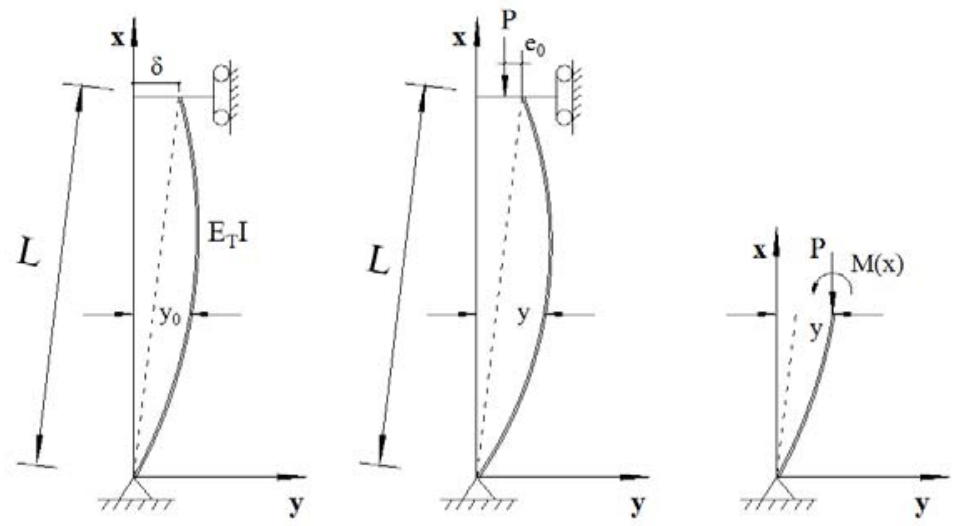

Figure 1. Mechanical Model of a Steel Column with Simply Fixed Ends

Because the displacement at the two ends of the column is fixed, the following boundary conditions can be adopted:

$y(0)=0, \quad y(L)=\delta$

For convenience, the following parameters are used:

$$
P_{c r}=\pi^{2} E_{T} I / L^{2}, u=\sqrt{P / P_{c r}}
$$

The general solution to Eq. 2 is given by

$$
y(x)=C_{1} \sin \left(\frac{u \pi x}{L}\right)+C_{2} \cos \left(\frac{u \pi x}{L}\right)+\frac{a_{0}}{1-u^{2}} \sin \left(\frac{\pi x}{L}\right)+\left(\delta-e_{0}\right)
$$

where parameters $\mathrm{C}_{1}$ and $\mathrm{C}_{2}$ are determined by employing the boundary condition (Eq. 3 ) as

$$
\begin{aligned}
& C_{1}=-\left(\left(e_{0}-\delta\right) \cos (u \pi)-e\right) / \sin (u \pi) \\
& C_{2}=e_{0}-\delta
\end{aligned}
$$


By using the yielding of the edge fibre at the maximum displacement of the column as the failure criterion, the ultimate load bearing capacity of a column with initial lateral displacement should be the solution for the following equation:

$$
\frac{P}{A}+\frac{P\left(\alpha_{\max }-\delta+e_{0}\right)}{W}=f_{y T}
$$

where $\mathrm{A}$ is the area of cross-section of the column, $\mathrm{W}$ is the section flexure modulus of the column, $f_{\mathrm{yT}}$ is the yield strength of steel at temperature $\mathrm{T}$, and $\alpha_{\max }=\mathrm{y}\left(\frac{2 \mathrm{~L}}{3}\right)$.

Eq. 8 is a transcendental equation. Shift the right side of the equation to the left side.

Given the dimension of the steel column at a specified temperature distribution, the ultimate load bearing capacity can be obtained with Eq. 8 via the Newton iterative method.

\subsection{Steel Columns with Both Ends Rigidly Supported}

The initial flexure of the column can be expressed by

$y_{0}=\frac{1}{2} a_{0}\left(1-\cos \frac{2 \pi}{L} x\right)+\frac{\delta \cdot x}{L}$

where $\mathrm{L}$ is the length of the column, $\mathrm{a}_{0}$ is the initial flexure at the mid-span of the column and $\delta$ is the initial lateral displacement.
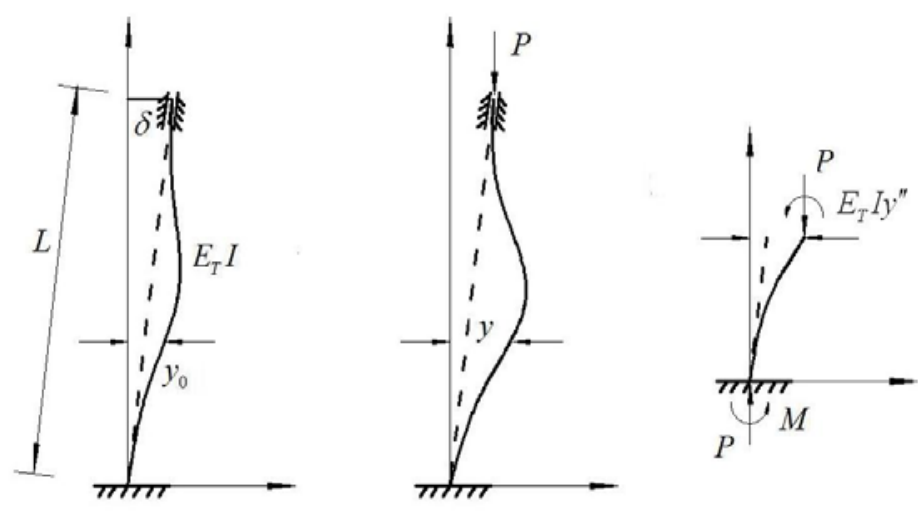

Figure 2. Mechanical Model of a Steel Column with Simple Rigidly Fixed Ends

Figure 2 shows the mechanical model of a steel column with rigidly fixed boundary conditions. According to the differential equation for equilibrium, if the lateral displacement of the column under the action of a vertical load is represented by $\mathrm{y}$, then the following equation can be obtained: 
$E_{T} I\left(y-y_{0}\right)^{\prime \prime}+P(y-\delta)+\mathrm{M}=0 \quad(0 \leq x \leq L)$

The following boundary conditions can be adopted:

$$
\left\{\begin{array}{l}
y(0)=0 \\
y(L)=\delta \\
y^{\prime}(0)=0
\end{array}\right.
$$

The general solution to Eq. 10 is given by

$$
\mathrm{y}(x)=C_{1} \sin \left(\frac{\sqrt{P} x}{\sqrt{E_{\mathrm{T}} I}}\right)+C_{2} \cos \left(\frac{\sqrt{P} x}{\sqrt{E_{\mathrm{T}} I}}\right)+\frac{2 E_{\mathrm{T}} I a_{0} \pi^{2} P}{P\left(P L^{2}-4 \pi^{2} E_{\mathrm{T}} I\right)} \cos \left(2 \frac{\pi x}{L}\right)-\frac{M-\delta P}{P}
$$

where parameters $\mathrm{C} 1, \mathrm{C} 2$ and $\mathrm{M}$ are determined by employing the boundary condition of Eq. 11 as

$$
\begin{aligned}
C_{1}= & -\left(-2 E_{\mathrm{T}} I a_{0} \pi^{2} P+L^{2} M P-4 M \pi^{2} E_{\mathrm{T}} I+2 \cos \left(\frac{\sqrt{P} L}{\sqrt{E_{\mathrm{T}} I}}\right) E_{\mathrm{T}} I a_{0} \pi^{2} P-4 \cos \left(\frac{\sqrt{P} L}{\sqrt{E_{\mathrm{T}} I}}\right) \delta P \pi^{2} E_{\mathrm{T}} I+\cos \left(\frac{\sqrt{P} L}{\sqrt{E_{\mathrm{T}} I}}\right) L^{2} \delta P^{2}\right. \\
& \left.-\cos \left(\frac{\sqrt{P} L}{\sqrt{E_{\mathrm{T}} I}}\right) L^{2} M P+4 \cos \left(\frac{\sqrt{P} L}{\sqrt{E_{\mathrm{T}} I}}\right) M \pi^{2} E_{\mathrm{T}} I\right) \sin \left(\frac{\sqrt{P} \mathrm{~L}}{\sqrt{E_{\mathrm{T}} I}}\right)^{-1} P^{-1}\left(-P L^{2}+4 \pi^{2} E_{\mathrm{T}} I\right)^{-1} \\
C_{2}= & \frac{\left(2 E_{\mathrm{T}} I a_{0} \pi^{2} P-4 \delta P \pi^{2} E_{\mathrm{T}} I+L^{2} \delta P^{2}-L^{2} M P+4 M \pi^{2} E_{\mathrm{T}} I\right)}{P\left(-P L^{2}+4 \pi^{2} E_{\mathrm{T}} I\right)} \\
M= & -\frac{P\left(-2 E_{\mathrm{T}} I a_{0} \pi^{2}+2 \cos \left(\frac{\sqrt{P} L}{\sqrt{E_{\mathrm{T}} I}}\right) E_{\mathrm{T}} I a_{0} \pi^{2}-4 \cos \left(\frac{\sqrt{P} L}{\sqrt{E_{\mathrm{T}} I}}\right) \delta \pi^{2} E_{\mathrm{T}} I+\cos \left(\frac{\sqrt{P} L}{\sqrt{E_{\mathrm{T}} I}}\right) L^{2} \delta P\right)}{P L^{2}-4 \pi^{2} E_{\mathrm{T}} I-\cos \left(\frac{\sqrt{P} L}{\sqrt{E_{\mathrm{T}} I}}\right) L^{2} P+4 \cos \left(\frac{\sqrt{P} L}{\sqrt{E_{\mathrm{T}} I}}\right) \pi^{2} E_{\mathrm{T}} I}
\end{aligned}
$$

By using the yielding of the edge fibre at the mid-span of the column as the failure criterion, the ultimate load bearing capacity of the column with initial lateral displacement should be the minimum solutions to the following two equations:

$$
\left\{\begin{array}{l}
\frac{P}{A}+\frac{M}{W}=f_{y T} \\
\frac{P}{A}+\frac{\left|M-P \alpha_{\max }\right|}{W}=f_{y T}
\end{array}\right.
$$


where $\mathrm{A}$ is the cross-sectional area of the column, $\mathrm{W}$ is the section flexure modulus of the column, $f_{\mathrm{yT}}$ is the yield strength of steel at temperature T, and $\alpha_{\max }=y\left(\frac{L}{2}\right)$.

Given the dimensions of a steel column at a specific temperature distribution, the ultimate load bearing capacity can be obtained with Eq. 16 by determining the simplest solution.

\subsection{Validation of the Deflection Curve via FEM}

To verify the equation of the deflection curve proposed in the paper, two FEM models are presented using ANSYS software. The element type used in the analysis is BEAM3, a uniaxial element with compression, tension, and bending capabilities. The element has three degrees of freedom at each node: translations in the nodal $\mathrm{x}$ and $\mathrm{y}$ directions and rotation about the nodal $\mathrm{z}$-axis. The length of the element is $50 \mathrm{~mm}$.

The mechanical properties of steel at an increased temperature is recommended in the Chinese Technical Code on Fire Safety of Steel Building Structures [18]. Young's modulus at elevated temperatures can be obtained by the following formula:

$$
\begin{aligned}
& E_{\mathrm{T}}=\chi_{\mathrm{T}} E \\
& \chi_{\mathrm{T}}= \begin{cases}\frac{7 T_{\mathrm{s}}-4780}{6 T_{\mathrm{s}}-4760} & 20{ }^{\circ} \mathrm{C} \leq T_{\mathrm{s}}<600^{\circ} \mathrm{C} \\
\frac{1000-T_{\mathrm{s}}}{6 T_{\mathrm{s}}-2800} & 600^{\circ} \mathrm{C} \leq T_{\mathrm{s}} \leq 1000^{\circ} \mathrm{C}\end{cases}
\end{aligned}
$$

where $T_{s}$ is the temperature of the column, $E_{T}$ is the elastic modulus of steel at temperature $T_{s}, E$ is the elastic modulus of steel at room temperature, and $\chi_{\mathrm{T}}$ is the reduction coefficient of the elastic modulus at elevated temperature.

The yield strength of steel at elevated temperature can be obtained by the following formula:

$$
\begin{aligned}
& f_{\mathrm{yT}}=\eta_{\mathrm{T}} f_{\mathrm{y}} \\
& \eta_{\mathrm{T}}=\left\{\begin{array}{cc}
1.0 & 20^{\circ} \mathrm{C} \leq T_{\mathrm{s}} \leq 300^{\circ} \mathrm{C} \\
1.24 \times 10^{-8} T_{\mathrm{s}}^{3}-2.096 \times 10^{-5} T_{\mathrm{s}}^{2} & \\
+9.228 \times 10^{-3} T_{\mathrm{s}}-0.2168 & 300^{\circ} \mathrm{C}<T_{\mathrm{s}}<800^{\circ} \mathrm{C} \\
0.5-T_{\mathrm{s}} / 2000 & 800^{\circ} \mathrm{C} \leq T_{\mathrm{s}} \leq 1000^{\circ} \mathrm{C}
\end{array}\right.
\end{aligned}
$$

where $f_{\mathrm{yT}}$ is the yield strength of steel at temperature $\mathrm{T}_{\mathrm{s}}, f_{\mathrm{y}}$ is the yield strength of steel at room temperature, and $\eta_{\mathrm{T}}$ is the reduction coefficient of yield strength at elevated temperature. 
Model 1 is used to verify the flexure shape of the steel column, the most important parameter in defining the ultimate load capacity of the steel column with initial lateral displacement. In this model, the column section is $\mathrm{H} 300 \times 300 \times 8 \times 16$, with $\mathrm{L}=5 \mathrm{~m}, \xi=0.001, \mathrm{P}=3,000 \mathrm{kN}$, and $f \mathrm{y}=235$ $\mathrm{N} / \mathrm{mm}^{2}$. The temperature of the column with damaged fire protection is $600^{\circ} \mathrm{C}$. The results obtained by ANSYS and the proposed approach in this paper are shown in Figure 3; there is general agreement between the FEM and the formula proposed in this paper.

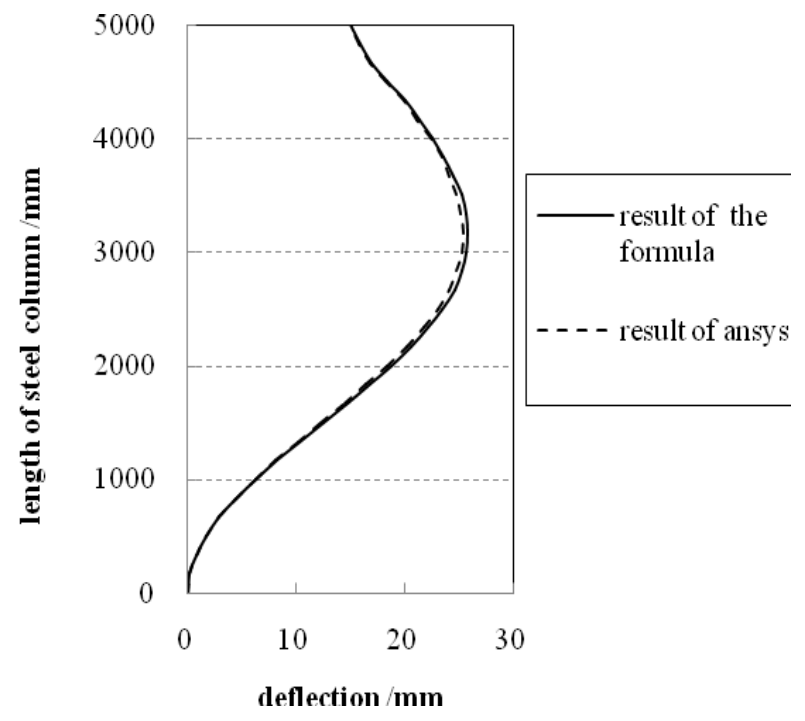

Figure 3. Comparison of the Deflections of the Both-Ends-Hinged Steel Column obtained with ANSYS and the Proposed approach

Model 2 is used to validate the mid-span displacement of the steel column with initial lateral displacement at the top end of the column under different vertical loads $\mathrm{P}$. In this model, the column section is $\mathrm{H} 300 \times 300 \times 8 \times 16$, with $\mathrm{L}=5 \mathrm{~m}, \xi=0.001, \delta=15 \mathrm{~mm}$, and $f \mathrm{y}=235 \mathrm{~N} / \mathrm{mm}^{2}$. The temperature of the column is $600^{\circ} \mathrm{C}$. The results obtained with ANSYS and the proposed approach in this paper are shown in Figure 4. The mid-span displacement predictions obtained with the method proposed in this paper concur with those obtained by the FEM.

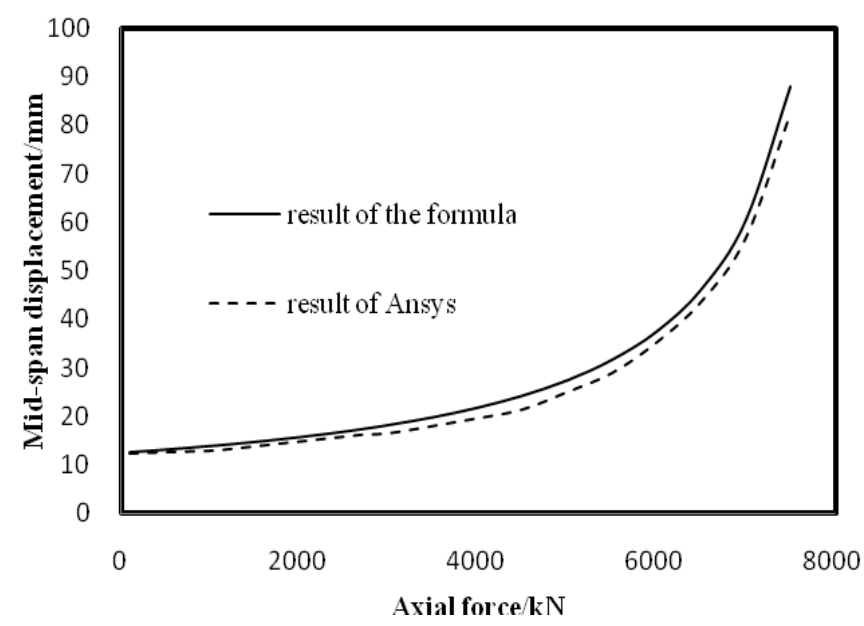

Figure 4. Comparison of the Mid-span Displacements of the Both-ends-hinged-supported Steel Column obtained with ANSYS and the Proposed Approach 


\subsection{Parametric Analysis}

To understand the behaviour of a steel column with initial lateral displacement at the top end during a fire, a column is analysed using the proposed model as an example.

The load bearing capacity coefficient of a steel column with initial lateral displacement is defined as

$\varphi_{T}=\frac{P}{f_{y 20} A}$

We can study the variation of the bearing capacity coefficient along with the change in initial lateral displacement, temperature, initial bending, load eccentricity and slenderness by considering a typical steel column with section $H 300 \times 300 \times 8 \times 16$.

In this part, we analyse how the initial lateral displacement and temperature affect axially restrained steel columns with both ends having hinged support. Because the initial lateral displacement and temperature are the most relevant parameters for this paper, study of other parameters will be researched in another paper.

The main characteristic parameters of the column are the initial bending rate, $\xi=1 \%$, the load eccentricity, $e_{0}=4 \%$, and the length of the column, $\mathrm{L}=5 \mathrm{~m}$. The curve?curves of the load bearing capacity coefficient versus temperature for different initial lateral displacements is?are plotted in Figure 5.

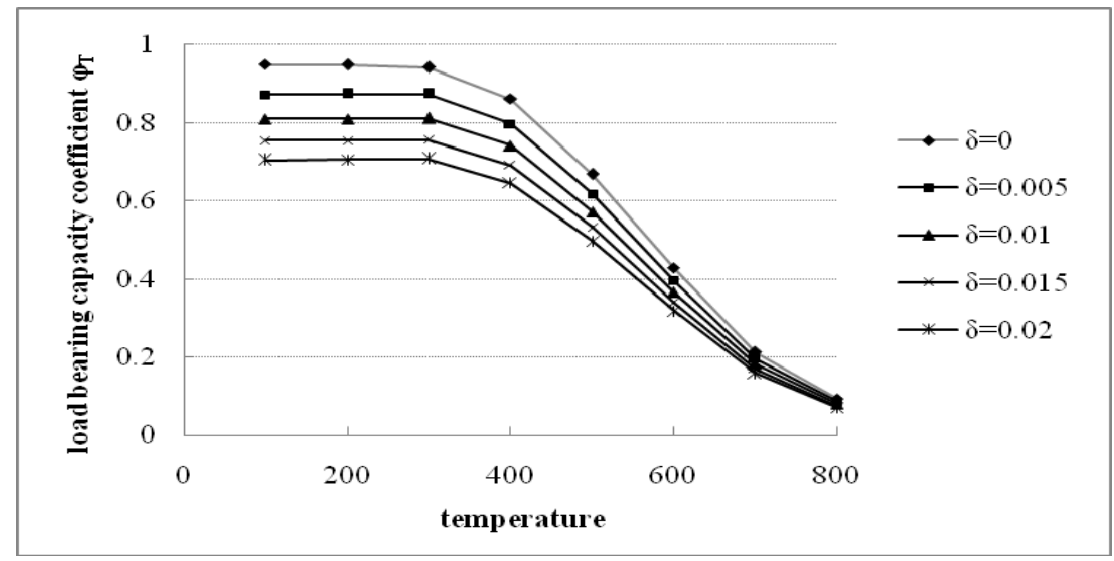

Figure 5. Load Bearing Capacity Coefficient-temperature Curve of the Example Steel Column

Figure 5 illustrates that regardless of the initial lateral displacement, when the temperature is in the range of $100-300^{\circ} \mathrm{C}$, the load bearing capacity coefficient remains essentially unchanged; when the temperature exceeds $300^{\circ} \mathrm{C}$, the load bearing capacity coefficient decreases notably with increasing temperature. When the temperature reaches $800^{\circ} \mathrm{C}$, the bearing capacity coefficient is approximately zero. 


\section{AXIAL FORCE OF AXIALLY RESTRAINED STEEL COLUMNS AT HIGH TEMPERATURES}

\subsection{Axial Force of Axially Restrained Steel Columns}

If an axially restrained column (e.g., a column in a frame) is heated via a fire, additional axial forces will be produced in the column as a result of thermal expansion; this is schematically illustrated in Figure 6.
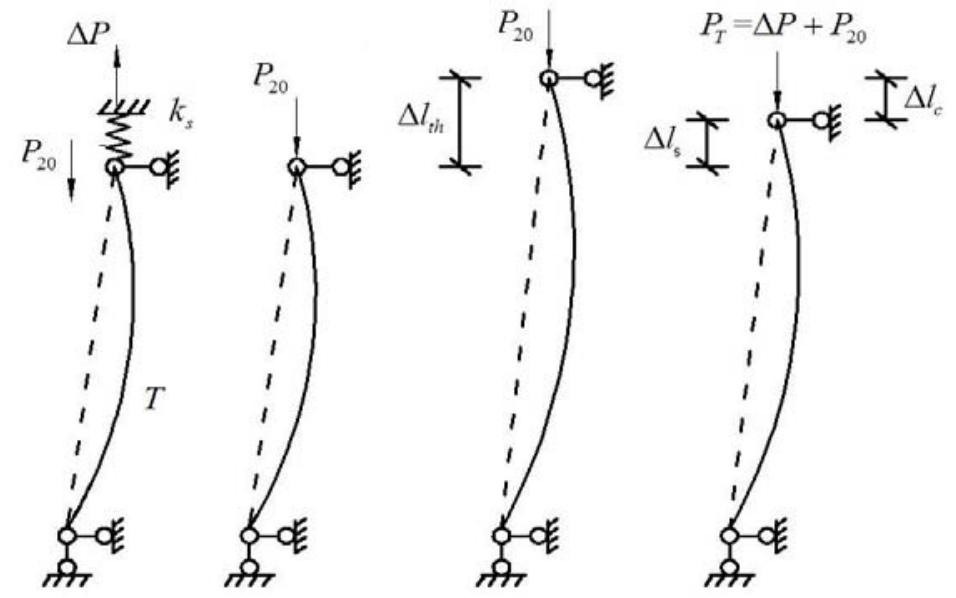

(a) Both ends hinged supported
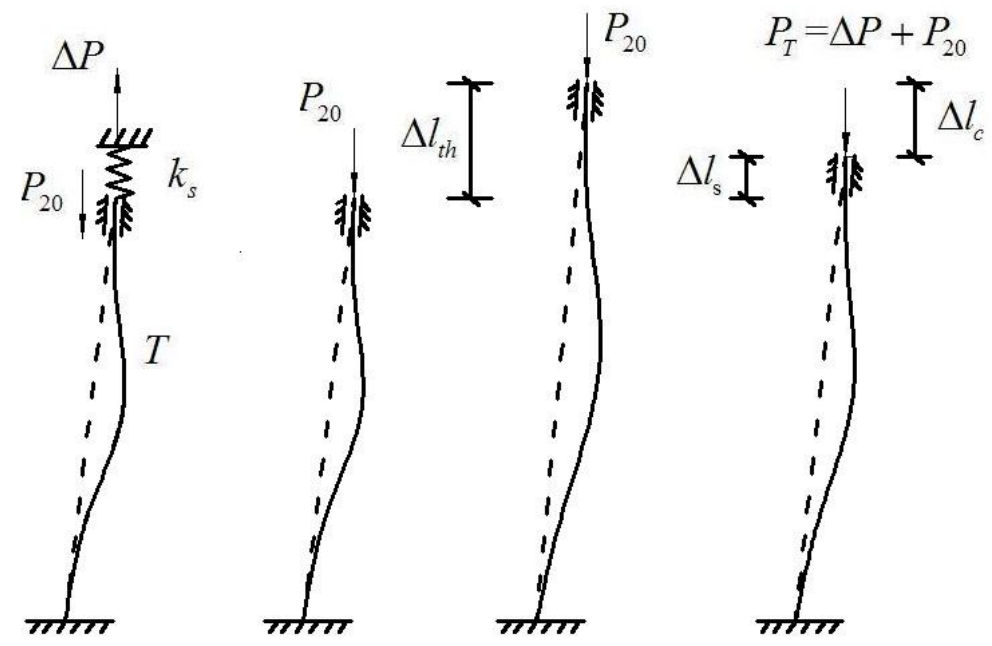

(b) Both ends rigidly supported

Figure 6. Model of a Restrained Steel Column 
As the temperature increases, the overall thermal expansion of the column can be obtained as

$$
\Delta l_{t h}=\alpha_{T}\left(T_{1}-T_{0}\right) \times L
$$

where $\alpha_{T}$ is the thermal expansion coefficient of the steel columns and $T_{0}$ is the normal temperature.

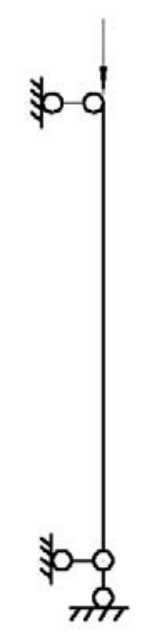

(a) Initial state

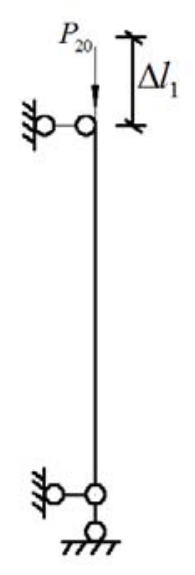

(b) Compressive state

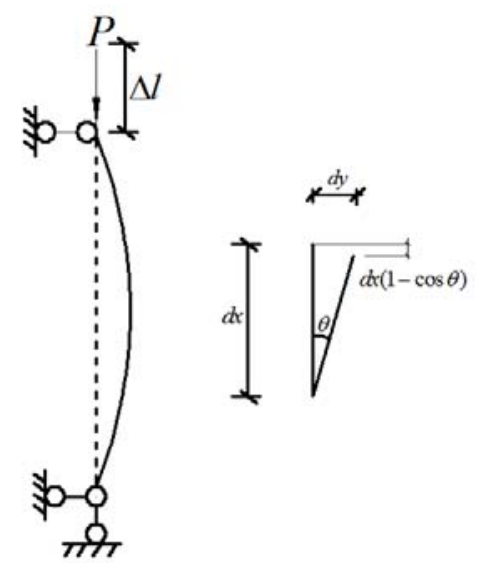

(c) Flexural state

Figure 7. Representation of the Change in the Length of a Column under Compression

(b) and bending (c)

At increased temperatures, the column will become shorter because of the decrease in the elastic modulus and the increase in the axial compressive force. In addition, bending will also shorten the length of the column. As illustrated in Figure 7(b), the change in the length of a steel column at two different axial forces and different elastic moduli can be represented as

$\Delta l_{2}-\Delta l_{1}=\frac{P_{T} \times L}{E_{T} A}-\frac{P_{20} \times L}{E A}$

As shown in Figure 7(c),

$$
\begin{aligned}
& \cos \theta=1-\frac{1}{2} \theta^{2}+\frac{1}{24} \theta^{4}+\cdots \approx 1-\frac{1}{2} \theta^{2}, \theta=\frac{d y}{d x}=y^{\prime}, \text { so } \\
& d x(1-\cos \theta)=\left(\frac{1}{2}\right) \theta^{2} d x=\frac{1}{2}\left(y^{\prime}\right)^{2} d x
\end{aligned}
$$


Therefore, the change in the length of the column resulting from bending can be represented as

$$
\Delta l=\int_{0}^{L}(1-\cos \theta) d x \approx \frac{1}{2} \int_{0}^{L}\left(y^{\prime}\right)^{2} d x
$$

According to the above formula, the complete shrinkage of the column with initial lateral displacement can be determined by

$$
\Delta l_{c}=\frac{P_{T} \times L}{E_{T} A}-\frac{P_{20} \times L}{E A}+\frac{1}{2} \int_{0}^{L}\left[y^{\prime}\left(P_{T}\right)^{2}-y^{\prime}\left(P_{20}\right)^{2}\right] d_{x}
$$

where $\mathrm{P}_{\mathrm{T}}$ is the axial force of the column at increased temperatures and $\mathrm{P}_{20}$ is the axial force of the column at room temperature. $\mathrm{y}\left(\mathrm{P}_{\mathrm{T}}\right)$ is the lateral displacement of the column under the action of vertical load $\mathrm{P}_{\text {T. }} \mathrm{y}\left(\mathrm{P}_{20}\right)$ is the lateral displacement of the column under the action of vertical load $\mathrm{P}_{20}$.

The spring representing the axial restraint will be compressed due to the increase in axial force. The length change of the compressed spring can be given by Hooke's law, i.e.,

$$
\Delta l_{\mathrm{s}}=\Delta P / k_{\mathrm{s}}
$$

where $\Delta \mathrm{P}=\mathrm{P}_{\mathrm{T}}-\mathrm{P}_{20}$ and $\mathrm{k}_{\mathrm{s}}$ is the axial restraint stiffness of the column.

As shown in Figure 7, the following equation can be obtained and employed to determine the axial force in the column at an elevated temperature:

$\alpha_{T}\left(T_{1}-20\right) \times L=\frac{P_{T}-P_{20}}{k_{s}}+\frac{P_{T} \times L}{E_{T} A}-\frac{P_{20} \times L}{E A}+\frac{1}{2} \int_{0}^{L}\left[y^{\prime}\left(P_{T}\right)^{2}-y^{\prime}\left(P_{20}\right)^{2}\right] d_{x}$

\subsection{Validation of the Axial Displacement via FEM}

To verify the equation of axial displacement proposed in the paper, another FEM model (Model 3) is used to validate the axial displacement of the steel columns with increased temperature. The column section is $\mathrm{H} 300 \times 300 \times 8 \times 16$, with $\mathrm{L}=5 \mathrm{~m}, \xi=0.001$ and $\mathrm{P}_{20}=328 \mathrm{kN}$. The thermal expansion coefficient is $\alpha=1.4 \times 10^{-5}$. The spring stiffness is $\mathrm{k}_{\mathrm{s}}=0.02 \times \mathrm{E}_{20} \mathrm{~A} / \mathrm{L}$. Comparisons of the development of the axial displacement obtained using the model proposed in this paper and the FEM method are shown in Figure 8. The axial displacement predictions obtained with the method proposed in this paper correspond well with those obtained by the FEM. 


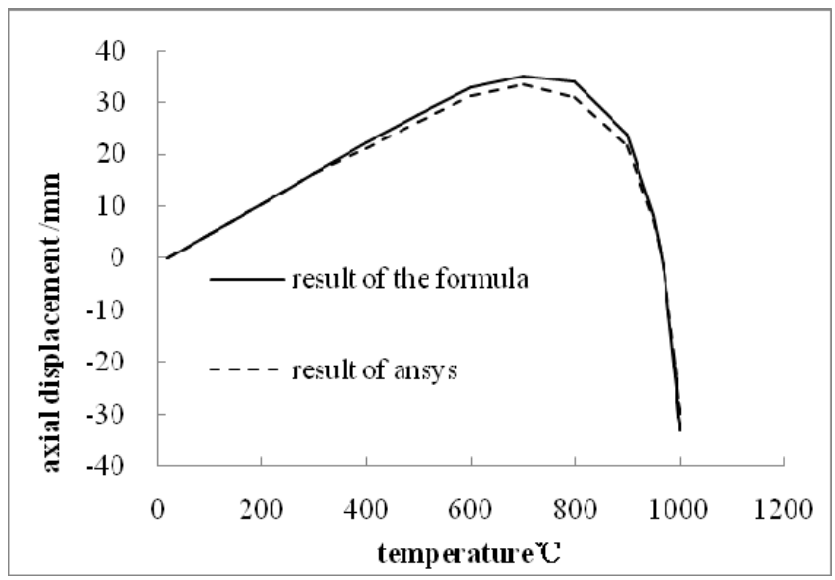

Figure 8. Comparison of the Axial Displacements of a Steel Column with Fixed Ends obtained with ANSYS and the Proposed Approach

\subsection{Parametric Analysis}

The axially restrained example column with initial lateral displacement is also examined to study the variation of the axial force in the column with increasing temperature. The relationships between the temperature of the column and the axial force in the column with various restraint stiffnesses and load ratios are illustrated in Figure 9; $\chi$ is the load ratio and $\zeta$ is the axial restraint ratio of the column and are defined as respectively, where $f_{\mathrm{y} 20}$ is the yield strength of the steel at a normal temperature.

$\chi=\frac{P_{20}}{f_{y 20} A}, \zeta=\frac{k_{s}}{E_{20} A / L}$

As shown in Figure 9, the axial force in the column with initial lateral displacement and axial restraint initially increases with increasing temperature. The axial force then decreases to the initial level with increasing temperature, possibly because the steel column has a large flexural deformation when the axial force has been released. When considering the same load ratio, a larger stiffness ratio will cause the axial force to increase further at high temperatures. When considering the same stiffness ratio, a larger load ratio will result in a lower axial force at high temperatures.

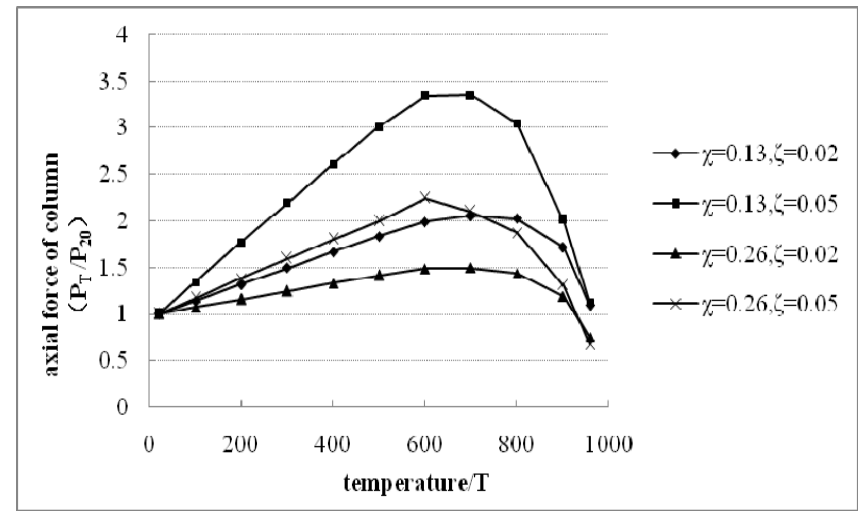

Figure 9. Axial Force in the Steel Column Example 


\section{CRITICAL TEMPERATURE OF AXIALLY RESTRAINED STEEL COLUMNS}

The axial force of steel columns subjected to fire may increase because of the restraint in the thermal elongation. When the axial force reaches the ultimate load bearing capacity in a fire, the column will fail. The critical temperature of the column with initial lateral displacement in a fire is defined as the temperature at which the increasing axial force equals the decreasing ultimate load bearing capacity of the column. For a given steel column, the ultimate load bearing capacity of the column can be calculated by Eq. 8 or Eq. 16. Given a specific restraint stiffness, the axial force of steel columns subjected to a fire can be determined using Eq. 25. The critical temperature of the columns can thus be obtained.

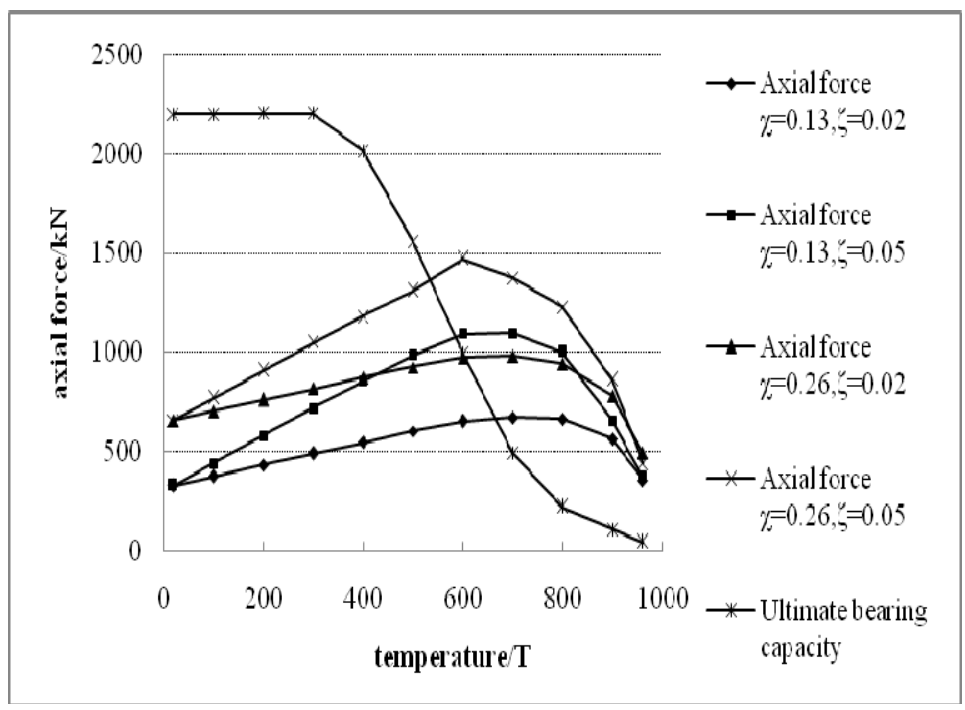

Figure 10. Critical Temperature of the Axial Restraint in the Steel Column Example

Figure 10 shows the critical temperature of both ends of simply hinged supported steel columns with different constraint stiffnesses and load ratios; the figure shows that the critical temperature decreases with increases in the constraint stiffness and load ratio.

\section{CONCLUSIONS}

Using an experimental approach to predict the fire resistance of a steel column is both time consuming and expensive. As an alternative, theoretical analysis that can be simply performed is a convenient tool for engineers to rapidly evaluate the fire resistance of a column. This paper presented an analytical model to determine the behaviour of restrained steel columns with initial lateral displacement in a fire. The ultimate load bearing capacity and critical temperature of steel columns can be predicted by employing the proposed model. The model can also be used to assess the fire resistance and predict the critical temperature of steel columns with initial lateral displacement. 
The following conclusions can be drawn based on the numerical study on a typical steel column with initial lateral displacement:

(1) The load bearing capacity of a steel column with both hinged support sides exposed to a fire decreases linearly at a given temperature with increasing initial lateral displacement. The load bearing capacity will be lower at a higher temperature. The load bearing capacity of a steel column is approximately zero when the temperature reaches $800^{\circ} \mathrm{C}$.

(2) The axial force in the axially restrained column with initial lateral displacement initially increases with increasing temperature; once reaching a certain temperature, the axial force may suddenly decrease with increasing temperature.

(3) The critical temperature decreases with an increase in constraint stiffness and the axial force of the steel column at room temperature.

\section{ACKNOWLEDGMENTS}

The work presented in this article was supported by the National Natural Science Foundation of China (Grant No. 51178115) and a project funded by the Priority Academic Program Development of Jiangsu Higher Education Institutions.

\section{REFERENCES}

[1] Shepherd, P.G. and Burgess, I.W., "On the Buckling of Axially Restrained Steel Columns in Fire”, Engineering Structures, 2011,Vol.33, pp. 2832-2838.

[2] Young, B. and Ellobody, E., "Performance of Axially Restrained Concrete Encased Steel Composite Columns at Elevated Temperatures", Engineering Structures, 2011, Vol. 33, pp. 245-254.

[3] Li, G.Q. and Zhang, C., "Creep Effect on Buckling of Axially Restrained Steel Columns in Real Fires”, Journal of Constructional Steel Research, 2012, Vol.71, pp.182-188.

[4] Kwon, I.K. and Kwon, Y.B., "Structural Stability of Fire-resistant Steel (FR490) H-section Columns at Elevated Temperatures", Steel and Composite Structures, 2014, Vol. 17, No.1, pp.105-121.

[5] Wang, W.Y. and Li, G.Q., "Fire-resistance Study of Restrained Steel Columns with Partial Damage to Fire Protection", Fire Safety Journal, 2009, Vol. 44, pp.1088-1094.

[6] Shahrial, A.M., Muntasir, B.A.H.M., Shahriar, Q., Mahmud, A., Rafi, A.N.M. and Ahmad, R., "Fire Performance Curves for Unprotected HSS Steel Columns", Steel and Composite Structures, 2013, Vol.15, No.6, pp.705-724.

[7] Della Corte, G., Landolfo, R. and Mazzolani, F.M., "Post-earthquake Fire Resistance of Moment Resisting Steel Frames", Fire Safety Journal, 2003,Vol.38, No.7, pp.593-612.

[8] Della Corte G, De Matteis G, Landolfo R, et al., "Seismic Analysis of MR Steel Frames based on Refined Hysteretic Models of Connections", Journal of Constructional Steel Research, 2002, Vol. 58 No. 10, pp. 1331-1345.

[9] Mohmmad, H.Y., "Post-Earthquake Fire Performance of Building Structures", Concordia University Montreal, Quebec, Canada, 2008.

[10] Ji, L., Zhao, J.H., Zhai, Y. and Li, X.Z., "Effect of Axial Restraint on Fire Resistance Performance of Steel Column”, Journal of Architecture and Civil Engineering, 2006, Vol. 23, No.4, pp. 64-69. 
[11] Li, G.Q. and Guo, S.X., "Experiment on Restrained Steel Beams subjected to Heating and Cooling", Journal of Constructional Steel Research, 2008, Vol.64, pp.268-274.

[12] Liu, T.C.H., Fahad, M.K. and Davies, J.M., "Experimental Investigation of Behaviour of Axially Restrained Steel Beams in Fire", Journal of Constructional Steel Research, 2002, Vol. 58, pp. 1211-1230.

[13] Rodrigues, J.P.C., Neves, I.C. and Valente, J.C., "Experimental Research on the Critical Temperature of Compressed Steel Elements with Restrained Thermal Elonga- Tion”, Fire Safety Journal, 2000, Vol. 35, No. 2, pp. 77-98.

[14] Huang, Z.F. and Tan, K.H., "Analytical Fire Resistance of Axially Restrained Steel Columns”, Journal of Structural Engineering, ASCE, 2003, Vol. 129, No. 11, pp.1531-1537.

[15] Li, G.Q. and Guo, S.X., "Analysis of Restrained Heated Steel Beams during Cooling Phase", Steel and Composite Structures, 2009, Vol. 9, No. 3, pp. 191-108.

[16] Ellobody, E. and Young, B., "Investigation of Concrete Encased Steel Composite Columns at Elevated Temperatures", Thin-Walled Structures, 2010, Vol. 48, pp. 597-608.

[17] Wang, Y.C. and Davies, J.M., "Fire Tests of Non-sway Loaded and Rotationally Restrained Steel Column Assemblies", Journal of Constructional Steel Research, 2003, Vol. 59, No.3, pp. 359-383.

[18] Chinese Technical Code on Fire Safety of Steel Building Structures. (CECS200-2006), Beijing (in Chinese), 2006. 